\title{
Influence of Control on the Pitch Damping of a Floating Wind Turbine
}

Conference Paper NREL/CP-500-42589

March 2008

\author{
J.M. Jonkman
}

Presented at the 2008 ASME Wind Energy Symposium Reno, Nevada January 7-10, 2008

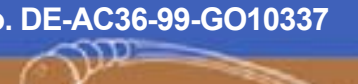




\section{NOTICE}

The submitted manuscript has been offered by an employee of the Midwest Research Institute (MRI), a contractor of the US Government under Contract No. DE-AC36-99G010337. Accordingly, the US Government and MRI retain a nonexclusive royalty-free license to publish or reproduce the published form of this contribution, or allow others to do so, for US Government purposes.

This report was prepared as an account of work sponsored by an agency of the United States government. Neither the United States government nor any agency thereof, nor any of their employees, makes any warranty, express or implied, or assumes any legal liability or responsibility for the accuracy, completeness, or usefulness of any information, apparatus, product, or process disclosed, or represents that its use would not infringe privately owned rights. Reference herein to any specific commercial product, process, or service by trade name, trademark, manufacturer, or otherwise does not necessarily constitute or imply its endorsement, recommendation, or favoring by the United States government or any agency thereof. The views and opinions of authors expressed herein do not necessarily state or reflect those of the United States government or any agency thereof.

Available electronically at http://www.osti.gov/bridge

Available for a processing fee to U.S. Department of Energy and its contractors, in paper, from:

U.S. Department of Energy

Office of Scientific and Technical Information

P.O. Box 62

Oak Ridge, TN 37831-0062

phone: 865.576 .8401

fax: 865.576 .5728

email: mailto:reports@adonis.osti.gov

Available for sale to the public, in paper, from:

U.S. Department of Commerce

National Technical Information Service

5285 Port Royal Road

Springfield, VA 22161

phone: 800.553 .6847

fax: 703.605.6900

email: orders@ntis.fedworld.gov

online ordering: http://www.ntis.gov/ordering.htm 


\title{
Influence of Control on the Pitch Damping of a Floating Wind Turbine*
}

\author{
Jason M. Jonkman ${ }^{\dagger}$ \\ National Renewable Energy Laboratory (NREL), Golden, Colorado, 80401-3393
}

\begin{abstract}
This paper presents the influence of conventional wind turbine blade-pitch control actions on the pitch damping of a wind turbine supported by an offshore floating barge with catenary moorings. There was a concern that the drop in steady-state wind turbine rotor thrust with wind speed above rated would lead to negative damping of the barge-pitch mode and contribute to the large system-pitch motions. It is demonstrated that neither the addition of a control loop through feedback of tower-top acceleration nor the modification to pitch-to-stall rotor-speed regulation satisfactorily improved the barge-pitch response. The latter modification helped conclude, however, that the actual barge-pitch damping was considerably greater than that implied by the steady-state rotor thrust response, but that it was still beneficial to increase the damping as much as possible. Detuning the gains in the baseline blade-pitch-to-feather controller helped, but still did not entirely resolve the bargepitch-motion problem.
\end{abstract}

\section{Nomenclature}

$A_{\text {Radiation }}=$ added inertia (added mass) associated with hydrodynamic radiation in pitch

$A_{\xi} \quad=$ amplitude of the platform-pitch oscillation

$B_{\text {Radiation }}=$ damping associated with hydrodynamic radiation in pitch

$B_{\text {Viscous }}=$ damping associated with hydrodynamic viscous drag in pitch

$C_{\text {Hydrostatic }}=$ hydrostatic restoring in pitch

$C_{\text {Lines }}=$ linearized hydrostatic restoring in pitch from all mooring lines

$C_{x} \quad=$ effective damping in the equation of motion for the platform pitch in terms of the translation of the hub

$I_{\text {Mass }}=$ pitch inertia associated with wind turbine and barge mass

$K_{P x} \quad=$ proportional gain in the tower-feedback control loop

$K_{x} \quad=$ effective stiffness in the equation of motion for the platform pitch in terms of the translation of the hub

$L_{H H} \quad=$ hub height

$M_{x} \quad=$ effective mass in the equation of motion for the platform pitch in terms of the translation of the hub

$T \quad=$ aerodynamic rotor thrust

$T_{0} \quad=$ aerodynamic rotor thrust at a linearization point

$V \quad=$ rotor-disk-averaged wind speed

$x=$ translational displacement of the hub

$\dot{x}=$ translational velocity of the hub

$\ddot{x}=$ translational acceleration of the hub

$\Delta \zeta_{x}=$ effective increase in the platform-pitch damping ratio

$\Delta \theta=$ small perturbation of the blade-pitch angles about their operating point

\footnotetext{
* Employees of the Midwest Research Institute under Contract No. DE-AC36-99GO10337 with the U.S. Dept. of Energy have authored this work. The United States Government retains, and the publisher, by accepting the article for publication, acknowledges that the United States Government retains a non-exclusive, paid-up, irrevocable, worldwide license to publish or reproduce the published form of this work, or allow others to do so, for the United States Government purposes.

† Senior Engineer I, National Wind Technology Center (NWTC), 1617 Cole Boulevard, AIAA Professional Member.
} 


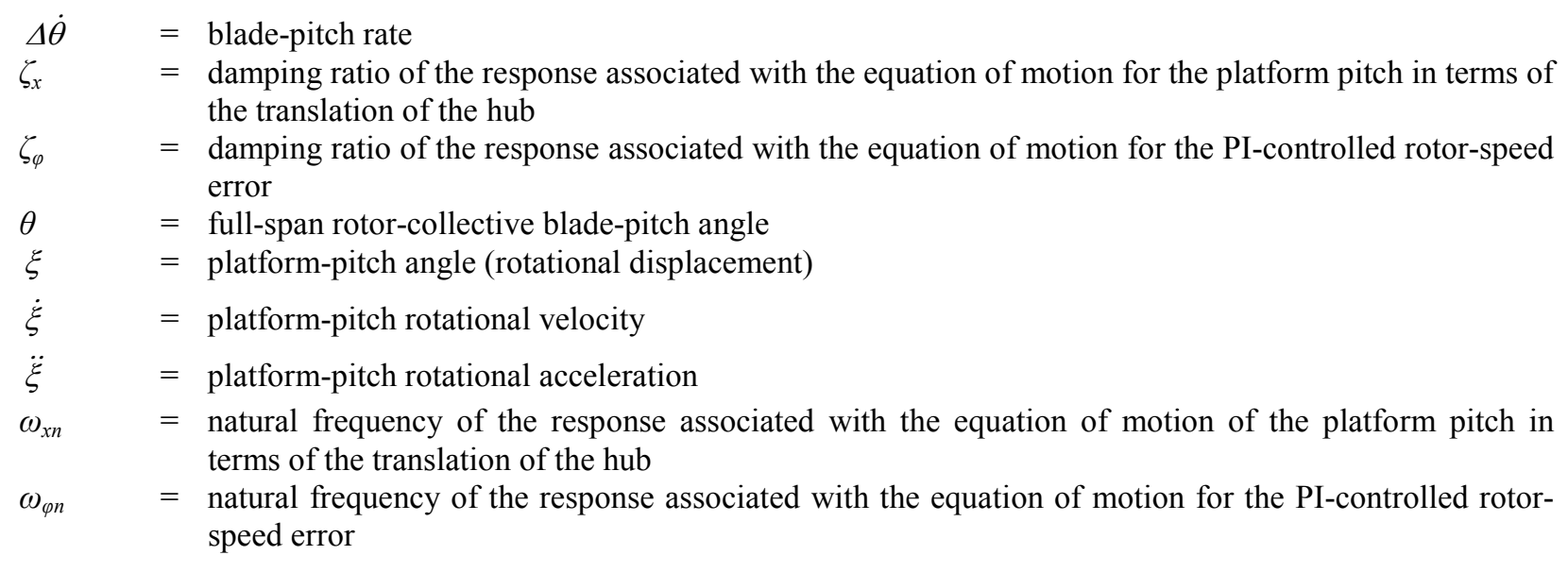

\section{Introduction}

TN previous work, ${ }^{1}$ Buhl and I performed a preliminary, but integrated, loads analysis for the National Renewable Energy Laboratory (NREL) 5-MW baseline wind turbine ${ }^{2}$ mounted both on land and offshore on the floating ITI Energy barge, ${ }^{3}$ which has slack, catenary moorings (see Figure 1 for an illustration of the offshore concept). By comparing the responses of the land- and sea-based systems, we were able to quantify the impact brought about by the dynamic couplings between the turbine and floating barge in the presence of combined wind and wave loading.

We used a simulation tool that can model the fully coupled time-domain aero-hydro-servo-elastic response of offshore floating wind turbines to run the loads analysis. I developed this capability by leveraging the computational methodologies and analysis tools of the onshore wind turbine and offshore oil and gas (O\&G) industries. The onshore wind-industry-accepted aero-servo-elastic turbine simulation capability of FAST (Fatigue, Aerodynamics, Structures, and Turbulence $)^{4}$ with AeroDyn ${ }^{5,6}$ has been interfaced with the external hydrodynamic wave-body interaction program WAMIT ${ }^{\circledR}$ (Wave Analysis at the Massachusetts Institute of Technology), ${ }^{7}$ which is commonly employed in the offshore O\&G industry. I established the interfaces among these simulation capabilities by developing modules for treating time-domain hydrodynamics (HydroDyn) and quasi-static mooring system responses. Figure 2 summarizes the modules and their interfaces. References 8 and 9 explain the theoretical framework and limitations of the recently developed hydrodynamic and mooring system modules in detail. In addition, Ref. 9 presents a model-to-model verification of these modules and of the fully coupled simulation tool.

To summarize the loads-analysis results presented in Ref. 1, the pitching motion of the barge brings about load excursions in the supported wind turbine that exceed those experienced by the turbine when it is installed on land. The load excursions are worse in the tower than in the blades because of the increased effect of inertia from the barge-pitch motion. To arrive at a technically feasible concept, the design will have to be modified, except possibly at the most sheltered of sites. Two forms of design modifications are possible. First, the turbine, especially the tower, could be strengthened to enable it to withstand the increased loading. However, this approach may not be cost-effective even though the wind turbine in an offshore floating system represents a smaller fraction of the total installed cost than in an onshore system. Second, design alterations may be able to improve

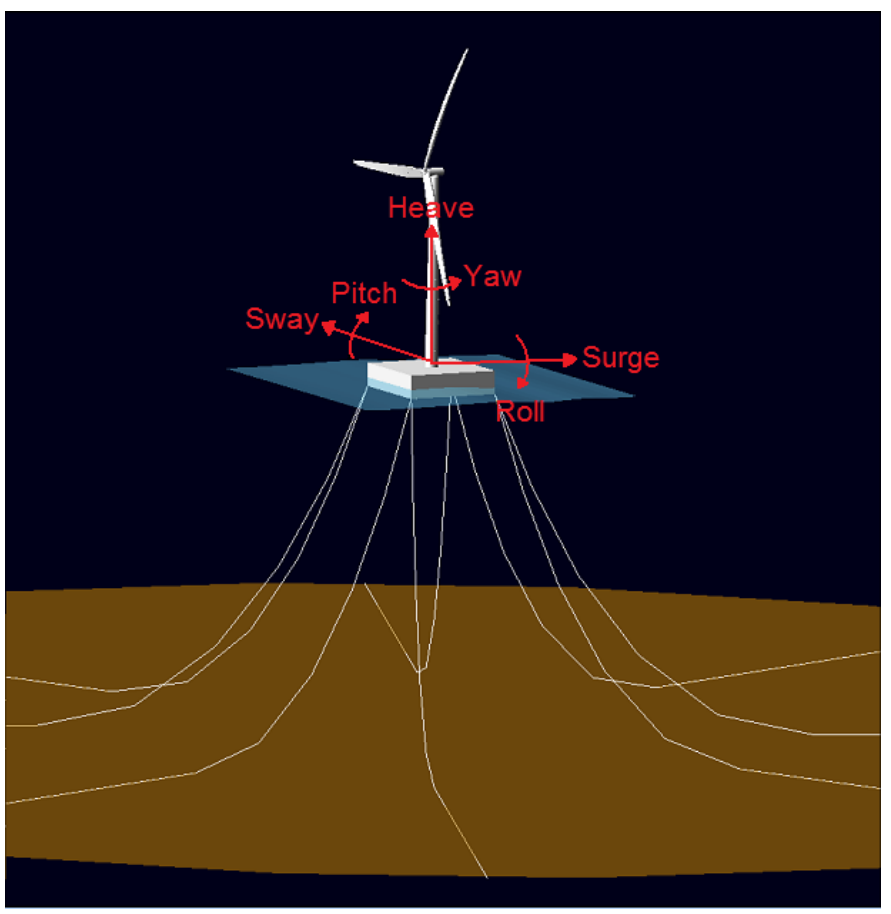

Figure 1. Illustration of the NREL 5-MW wind turbine on the ITI Energy barge. 


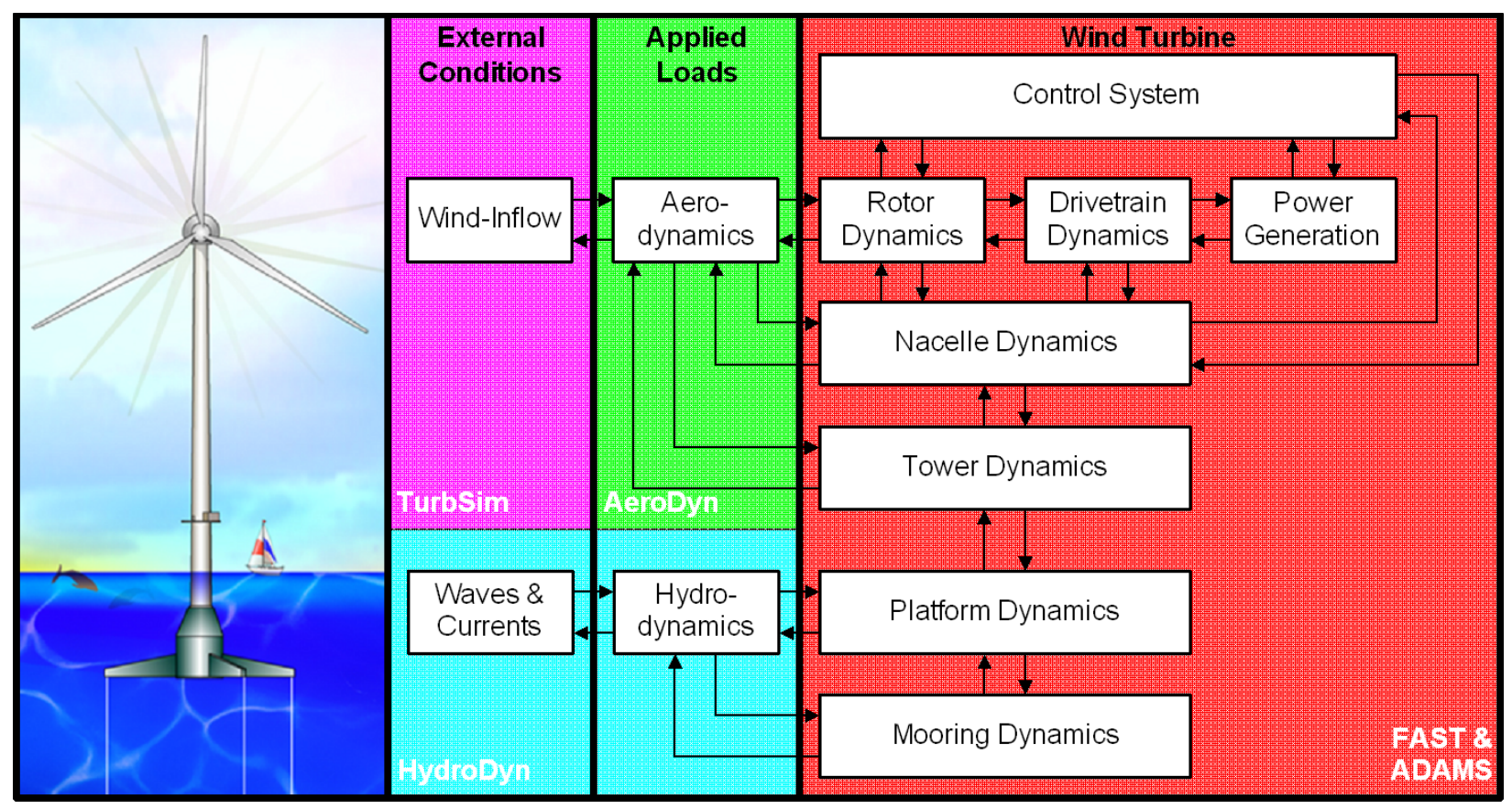

Figure 2. Interfacing modules to achieve fully coupled aero-hydro-servo-elastic simulation.

the response of the floating system to diminish the increases in loading.

One possible approach to improving the response of the floating system is to incorporate design features that will increase damping to stabilize the barge-pitch motion. Damping can be tailored through passive design features and active control. The NREL 5-MW baseline wind turbine I developed and used in the land- and sea-based loads analyses relied on a conventional variable-speed, variable blade-pitch-to-feather control system. The generator torque is computed as a tabulated function of the filtered generator speed, incorporating five control regions: 1 (start-up), 11/2 (transition), 2 (optimal power capture), 21/2 (transition), and 3 (constant power). In Region 3, the fullspan rotor-collective blade-pitch-angle commands are computed using gain-scheduled proportional-integral (PI) control of the rotor speed. ${ }^{2}$ A consequence of conventional pitch-to-feather control of wind turbines, though, is that steady-state rotor thrust is reduced with increasing wind speed above rated as shown in Figure 3. As pointed out by Nielsen, Hanson, and Skaare, ${ }^{10}$ "this effect may introduce negative damping in the system that may lead to large resonant motions of [a] floating wind turbine." As the loads-analysis results of Ref. 1 demonstrated, it is important that the damping of the barge-pitch mode be positive and kept as large as possible.

Section III addresses the influence of conventional wind turbine control methodologies to the pitch damping of the floating wind turbine system analyzed in Ref. 1. In this work, my aim was to modify the baseline control system of the NREL 5-MW turbine to improve the pitch damping of the ITI Energy barge. Moreover, I wanted to make these improvements by using conventional wind turbine control techniques to establish a modified baseline with

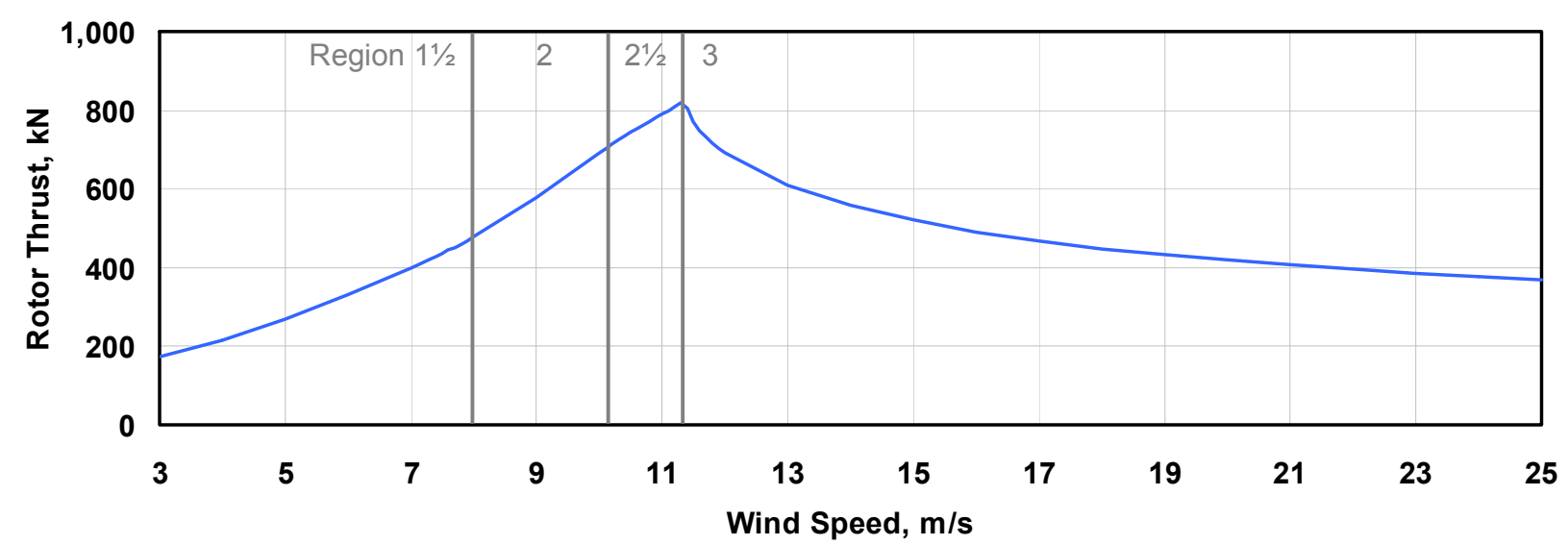

Figure 3. Steady-state rotor thrust as a function of wind speed for the NREL 5-MW baseline wind turbine. 
which I could compare more advanced or unconventional control scenarios. Even though I performed this work specifically for the NREL baseline wind turbine and the ITI Energy barge, the analysis process is valid for other concepts in which floating platforms support wind turbines controlled by blade pitch. Section IV qualitatively discusses other potential methods for improving the damping performance with wind turbine control.

First, however, it is important to describe the barge-pitch damping problem in more detail. Section II presents more details and a quantification of the problem.

\section{Overview of the Platform-Pitch-Damping Problem}

The barge-pitch damping problem can be analyzed by considering the rigid-body platform-pitch mode as a single degree of freedom (DOF). The equation of motion for this simple model is

$$
\left(I_{\text {Mass }}+A_{\text {Radiation }}\right) \ddot{\xi}+\left(B_{\text {Radiation }}+B_{\text {Viscous }}\right) \dot{\xi}+\left(C_{\text {Hydrostatic }}+C_{\text {Lines }}\right) \xi=L_{H H} T,
$$

where $\xi$ is the platform-pitch angle (i.e., rotational displacement), $\dot{\xi}$ is the platform-pitch rotational velocity, $\ddot{\xi}$ is the platform-pitch rotational acceleration, $I_{\text {Mass }}$ is the pitch inertia associated with wind turbine and barge mass, $A_{\text {Radiation }}$ is the added inertia (added mass) associated with hydrodynamic radiation in pitch, $B_{\text {Radiation }}$ is the damping associated with hydrodynamic radiation in pitch, $B_{\text {Viscous }}$ is the linearized damping associated with hydrodynamic viscous drag in pitch, $C_{\text {Hydrostatic }}$ is the hydrostatic restoring in pitch, $C_{\text {Lines }}$ is the linearized hydrostatic restoring in pitch from all mooring lines, $T$ is the aerodynamic rotor thrust, and $L_{H H}$ is the hub height (i.e., rotor-thrust moment arm).

Though not directly evident from Eq. (1), the aerodynamic rotor thrust also contributes to the platform-pitch damping. To consider its effect, it is convenient to state the equation of motion in terms of the translational motion of the hub instead of the pitching motion of the platform. For small pitch angles, the translational displacement of the hub, $x$, is linearly related to the platform-pitch angle by

$$
x=L_{H H} \xi .
$$

The aerodynamic rotor thrust depends on wind speed, rotor speed, and blade-pitch angle. To be clear, its dependence on the wind speed is actually a dependence on the relative wind speed at the hub because the hub can move in this simple model of the platform-pitch mode. If the hub translation varies slowly, the wake of the rotor will respond to changes in hub speed just as it does to changes in wind speed. Considering variations in aerodynamic rotor thrust with hub speed only, a first-order Taylor series expansion gives

$$
T=T_{0}-\frac{\partial T}{\partial V} \dot{x}
$$

where $T_{0}$ is the aerodynamic rotor thrust at a linearization point and $V$ is the rotor-disk-averaged wind speed.

The negative sign appears in Eq. (3) because, from Figure 1, positive platform-pitch angles correspond to downwind translational displacements of the hub, which reduces the relative wind speed. By combining Eqs. (1) through (3) and simplifying, the equation of motion of the platform-pitch mode stated in terms of the translational motion of the hub becomes

$$
\underbrace{\left(\frac{I_{\text {Mass }}+A_{\text {Radiation }}}{L_{H H}^{2}}\right)}_{M_{x}} \ddot{x}+\underbrace{\left(\frac{B_{\text {Radiation }}+B_{\text {Viscous }}}{L_{H H}^{2}}+\frac{\partial T}{\partial V}\right)}_{C_{x}} \dot{x}+\underbrace{\left(\frac{C_{H y d r o s t a t i c}+C_{\text {Lines }}}{L_{H H}^{2}}\right)}_{K_{x}} x=T_{0} .
$$

One can see that the isolated rigid-body platform-pitch DOF will respond as a second-order system with the natural frequency, $\omega_{x n}$, and damping ratio, $\zeta_{x}$, equal to

$$
\omega_{x n}=\sqrt{\frac{K_{x}}{M_{x}}}
$$




$$
\zeta_{x}=\frac{C_{x}}{2 \sqrt{K_{x} M_{x}}}
$$

Most of the terms in the effective mass, damping, and stiffness coefficients in Eq. (4) are easy to quantify. In particular, the terms related to the effective mass and stiffness, including the added inertia (added mass) in pitch and the linearized pitch restoring of the mooring system, are easily computed from a linearization analysis in FAST with HydroDyn. This linearization analysis resulted in a platform-pitch natural frequency for the ITI Energy barge with the NREL 5-MW baseline wind turbine of $\omega_{x n}=0.5420 \mathrm{rad} / \mathrm{s}=0.0863 \mathrm{~Hz}$.

Two terms in Eq. (4), the damping associated with hydrodynamic radiation in pitch, $B_{\text {Radiation }}$, and the thrust sensitivity to wind speed, $\partial T / \partial V$, are more difficult to quantify. The former is problematic because the hydrodynamic wave-radiation loads in the true linear hydrodynamic-loading expressions are actually described by a convolution integral, which is used to capture the wave-radiation memory effect. ${ }^{8}$ This convolution term is not convenient in this analysis or in the design of modern control systems. For use in controls engineering, for instance, Ref. 11 describes a method of converting the convolution term to state-space form by adding "radiation memory states." To avoid this complication in this analysis, however, I neglected the memory effect and approximated $B_{\text {Radiation }}$ as the amount of linear radiation damping at the platform-pitch natural frequency, $\omega_{x n}$. This choice is consistent with the linear time-domain representation of the frequency-domain problem that is described in Ref. 8 .

The thrust sensitivity to wind speed, $\partial T / \partial V$, can be computed in multiple ways. One way would be to estimate this sensitivity (at each wind speed) as the slope of the steady-state thrust versus wind-speed response presented in Figure 3. (Because the aerodynamic rotor thrust depends on wind speed, among other factors, the thrust sensitivity to wind speed depends on wind speed as well.) This way of computing the thrust sensitivity to wind speed characterizes the sensitivity of an ideal closed-loop blade-pitch speed-regulation system. I say "ideal" because a real blade-pitch control system responds to rotor-speed error (not variations in wind speed) and because the steady-state rotor speed is constant with wind speed throughout Region 3 where the rotor-speed control system functions. ${ }^{2}$

A second way of estimating the thrust sensitivity to wind speed would be to perform a linearization analysis in FAST with AeroDyn. FAST with AeroDyn could be used to compute $\partial T / \partial V$ at each of a number of given, steady, and uniform wind speeds and at the associated rotor speeds and blade-pitch angles from the steady-state response. This would be accomplished by perturbing the wind speed at each operating point and measuring the variation in the resulting aerodynamic thrust. (Within FAST, the central-difference-perturbation numerical technique is used to compute the partial derivative.) This way of computing the thrust sensitivity to wind speed characterizes the sensitivity of an open-loop system because the blade-pitch angle is not varied with the perturbations in wind speed.

I calculated $\partial T / \partial V$ using both methods. Using these thrust sensitivities to wind speed and other properties of the ITI Energy barge with the NREL 5-MW baseline wind turbine, I estimated the barge-pitch damping ratios according to Eq. (6). Figure 4 presents these ratios. I found the slope of the steady-state thrust versus wind-speed response in the ideal closed-loop method from the central-difference approximation of the derivative using the two wind speeds on either side of each given wind speed. This is why I did not estimate the barge-pitch damping ratios at the cut-in and cut-out wind speeds. The barge-pitch damping ratio is largest in magnitude and changes sign at the rated wind speed of $11.4 \mathrm{~m} / \mathrm{s}$ for the ideal closed-loop method, just like the thrust sensitivity to wind speed. Just above rated, the damping ratio is less than $-10 \%$. Near the cut-out wind speed of $25 \mathrm{~m} / \mathrm{s}$, the positive-valued hydrodynamic-radiation and viscous damping exceed the magnitude of the negative-valued aerodynamic damping,

\footnotetext{
This frequency falls in the range of typical sea states, which have peak spectral periods in the range of 5 to $20 \mathrm{~s}$ (see Ref. 1) corresponding to frequencies in the range of 0.05 to $0.2 \mathrm{~Hz}$ (i.e., 0.314 to $1.257 \mathrm{rad} / \mathrm{s}$ ). The barge will tend to oscillate at the excitation frequency of the incident waves, but the motions will be most severe when the wave-excitation frequency is at or near the barge's natural frequency. If the barge were to oscillate at its natural frequency with a pitch amplitude of $A_{\xi}$, the amplitude of the hub translational velocity would be $A_{\xi} L_{H H} \omega_{x r}$ and the amplitude of the hub translational acceleration would be $A_{\xi} L_{H H} \omega_{x n}^{2}$. For $A_{\xi}=5^{\circ}$, this translates into hub velocity and acceleration amplitudes of about $4.26 \mathrm{~m} / \mathrm{s}$ and $2.31 \mathrm{~m} / \mathrm{s}^{2}=0.24 \mathrm{~g}$ 's, respectively; for $A_{\xi}=10^{\circ}$, this translates into hub velocity and acceleration amplitudes of about $8.51 \mathrm{~m} / \mathrm{s}$ and $4.61 \mathrm{~m} / \mathrm{s}^{2}=0.47 \mathrm{~g}$ 's, respectively. At these amplitudes, the wind turbine control system will continuously switch between below- and above-rated control regions, except at the very lowest and highest mean hub-height wind speeds.
} 


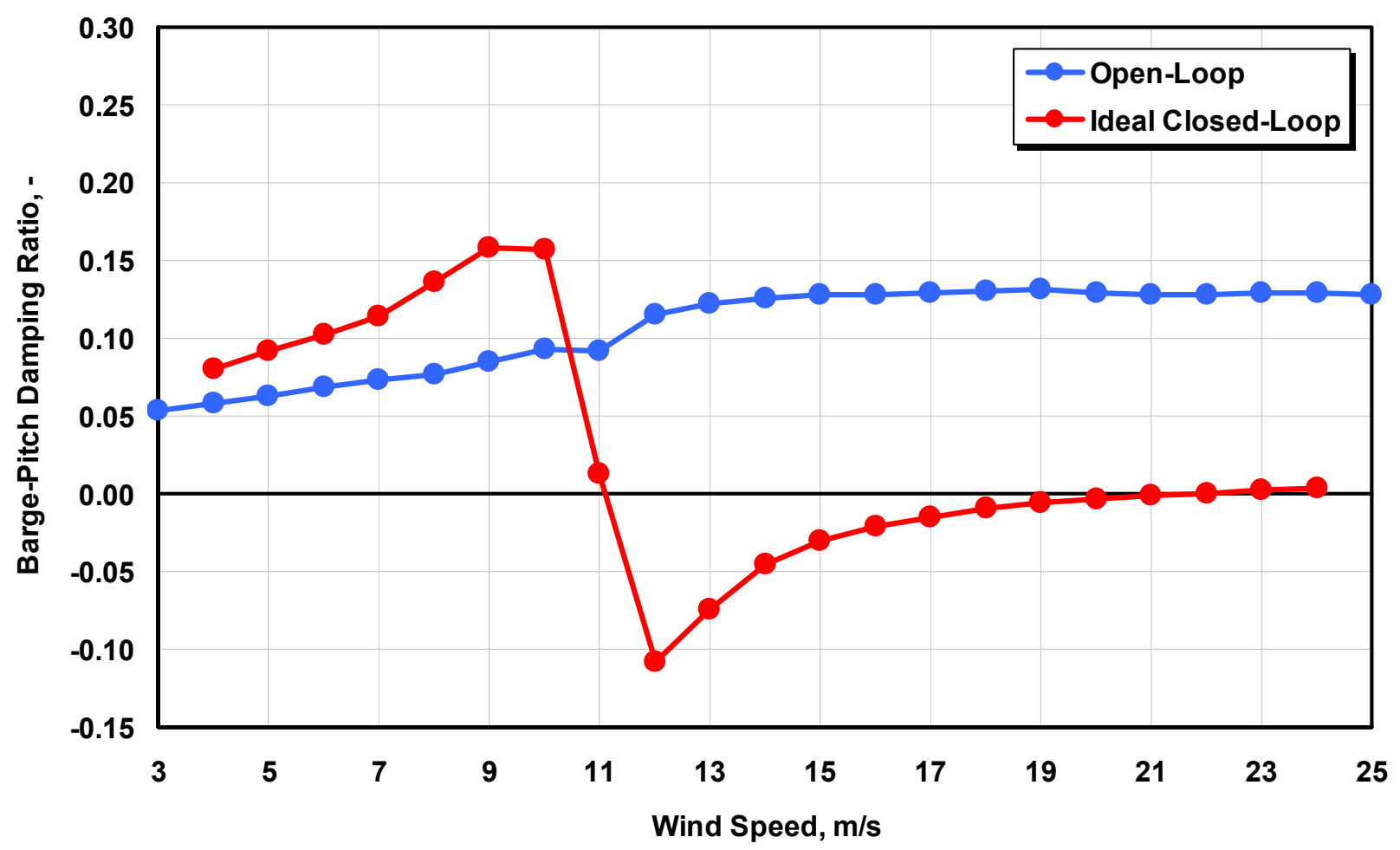

Figure 4. Pitch-to-feather barge-pitch damping ratios.

so the barge-pitch damping ratio becomes slightly positive again. In the open-loop method, the thrust sensitivity and barge-pitch damping ratio increase with wind speed below rated and remain flat and positive above rated. Consequently, the barge-pitch damping ratio remains positive across all wind speeds in the open-loop method. With real blade-pitch-control speed regulation above rated, the actual damping ratio is difficult to quantify with this simple model, but will fall somewhere between the bounds imposed by the open- and ideal closed-loop results.

\section{Influence of Conventional Wind Turbine Control Methodologies}

To improve the barge-pitch damping, I modified the baseline control system with a number of conventional wind turbine control methodologies. These included (A) adding a second blade-pitch control loop through feedback of tower-top acceleration, (B) changing from variable blade-pitch-to-feather to variable blade-pitch-to-stall speedcontrol regulation, and $(\mathrm{C})$ detuning the gains in the variable blade-pitch-to-feather rotor-speed controller. I developed and tested (through simulation) each approach independently. The rationale behind each approach and the main findings are presented in Sections III.A, III.B, and III.C, respectively.

\section{A. Feedback of Tower-Top Acceleration}

The conventional approach to improving the tower fore-aft damping in land-based wind turbines is to append the conventional blade-pitch controller for rotor-speed regulation with an additional blade-pitch control loop, which uses a tower-top acceleration measurement. ${ }^{12}$ Naturally, the same technique could be applied to modify the platform-pitch damping of an offshore floating wind turbine. The intent of the new control loop would be to augment the aerodynamic rotor thrust with adjustments to the blade-pitch angle based on the tower-top acceleration measurement. To see the effect of blade-pitch angle on the platform-pitch damping, consider variations in the aerodynamic thrust with full-span rotor-collective blade-pitch angles, $\theta$, in addition to hub speed, as was accounted for in Eq. (3):

$$
T=T_{0}-\frac{\partial T}{\partial V} \dot{x}+\frac{\partial T}{\partial \theta} \Delta \theta
$$


In Eq. (7), $\Delta \theta$ is a small perturbation of the blade-pitch angles about their operating point. If the blade-pitch rate in the tower-feedback (TFB) control loop is proportional to a tower-top acceleration measurement through a gain $K_{P x}$, then:

$$
\begin{gathered}
\Delta \dot{\theta}=K_{P x} \ddot{x} \\
\text { or } \\
\Delta \theta=K_{P x} \int_{0}^{t} \ddot{x} d t=K_{P x} \dot{x} .
\end{gathered}
$$

By combining Eqs. (8b) and (7) with the equations presented in Section II and simplifying, the addition of a TFB control loop modifies the effective damping coefficient from Eq. (4) and becomes

$$
C_{x}=\frac{B_{\text {Radiation }}+B_{\text {Viscous }}}{L_{H H}^{2}}+\frac{\partial T}{\partial V} \underbrace{-K_{P x} \frac{\partial T}{\partial \theta}}_{\text {New Term }} .
$$

The effective mass and stiffness coefficients from Eq. (4) are left unchanged by the addition of the TFB control loop.

In an active blade-pitch-to-feather wind turbine, the thrust sensitivity to rotor-collective blade pitch, $\partial T / \partial \theta$, is negative-valued from cut-in to cut-out so damping is increased with a positive control gain. Once the thrust sensitivity to rotor-collective blade pitch is known and a control gain is chosen, the effective increase in platformpitch damping ratio, $\Delta \zeta_{x}$, according to the given model is

$$
\Delta \zeta_{x}=-\frac{K_{P x}}{2 \sqrt{K_{x} M_{x}}}\left(\frac{\partial T}{\partial \theta}\right)
$$

Alternatively, a proper control gain can be chosen specifically from any desired increase in platform-pitch damping according to the given model. Just like the thrust sensitivity to wind speed, though, the thrust sensitivity to rotor-collective blade-pitch angle depends on the wind speed, rotor speed, and blade-pitch angle. Consequently, one cannot achieve a constant increase in damping ratio across control regions without gain-scheduling. The gainscheduling law for the TFB control system will not, however, be as simple as the law used in the blade-pitch rotorspeed-regulation controller, because the thrust sensitivity to blade pitch is not linearly related to the blade-pitch angle. I calculated the thrust sensitivity to blade pitch from a linearization analysis in FAST with AeroDyn.

In the middle of Region $3(18 \mathrm{~m} / \mathrm{s})$, a modest 0.05 increase in effective damping ratio requires a control gain of $K_{P x}=0.007556 \mathrm{rad} /(\mathrm{m} / \mathrm{s})$ and a large 0.5 increase in effective damping ratio requires a control gain of $K_{P x}=0.07556$ $\mathrm{rad} /(\mathrm{m} / \mathrm{s})$. Naturally, the larger the control gain, the larger the blade-pitch-rate requirement. Conversely, to limit the blade-pitch rate, one has to minimize the effective increase in damping ratio. From the footnote on page 2, bargepitch amplitudes in the range of $A_{\xi}=5$ to $10^{\circ}$ can result in hub-acceleration amplitudes ranging from 2.31 to 4.61 $\mathrm{m} / \mathrm{s}^{2}$. In the middle of Region 3, according to the given model, damping these motions using the TFB control loop developed previously will require blade-pitch-rate amplitudes in the range of $\Delta \dot{\theta}=1.0$ to $2.0^{\circ} / \mathrm{s}$ for the modest 0.05 increase in effective damping ratio and $\Delta \dot{\theta}=10.0$ to $20.0^{\circ} \mathrm{s}$ for the large 0.5 increase in effective damping ratio. Consequently, only moderately large increases in effective damping ratio are achievable with the given blade-pitchrate limit of $8 \%$ (from Ref. 2).

I incorporated the TFB control loop into my FAST with AeroDyn and HydroDyn simulations through a simple modification of the baseline control system. As implemented, I found the TFB blade-pitch angle commands by measuring the tower-top fore-aft acceleration, integrating to find the tower-top fore-aft velocity, and then multiplying by the control gain. This blade-pitch-angle command was then added to the blade-pitch-angle command from the rotor-speed controller, which had already been saturated for the angle and rate limits. Said another way, I did not saturate the TFB control system commands. 
For the NREL 5-MW wind turbine mounted atop the ITI Energy barge, I tested the system response at a variety of wind and wave conditions with both the modest and high TFB gains. Figure 5 shows a response with the high $K_{P x}=0.07556 \mathrm{rad} /(\mathrm{m} / \mathrm{s})$ TFB gain for a simulation with stochastic winds with a mean hub-height wind speed of 18 $\mathrm{m} / \mathrm{s}$ and irregular waves with a significant wave height of $3.673 \mathrm{~m}$ and a peak spectral period of $13.376 \mathrm{~s}$. (These waves have the expected value of the significant wave height and the median value of the peak spectral period conditioned on the mean hub-height wind speed at the chosen reference site; see Ref. 1.) The system response with the unmodified (baseline) control system is shown for comparison in Figure 5. I ran the simulations with all appropriate and available DOFs enabled, as applied in the loads analysis and described in Ref. 1, but without considering the rotor-mass imbalance or the increased blade structural-damping ratio. In Figure 5, the ordinates "GenPwr," "GenSpeed," "BlPitch1," and "PtfmPitch" correspond to the instantaneous electrical output of the generator, generator (high-speed shaft) rotational speed, pitch angle of the reference blade (Blade 1), and platformpitch angle, respectively.

It may seem surprising at first that the results do not show a large improvement in the damping of the barge-pitch motion ("PtfmPitch"). The exacerbated excursions in generator speed and electrical output are more prominent. These results can be understood by thinking about the problem in more detail than is provided in the simple model. The relative wind speed is highest when the system is pitching into the wind (i.e., from maximum to minimum barge-pitch angles). This causes the rotor-speed control system to pitch the blades to feather (more positive) to shed power and regulate speed while the TFB damping control system pitches the blades to stall (more negative) to increase thrust and introduce damping. The reverse is true when the turbine is pitching with the wind. In this case, the relative wind speed is lowest when the system pitches downwind, causing the rotor-speed control system to pitch the blades to stall while the TFB damping control system commands pitching to feather. Said another way, the two blade-pitch control systems are at odds and fight with each other in this situation. This can be seen by the bladepitch angle responses of Figure 5, where in many instances, the pitch-angle commands in the baseline control system move in the opposite direction to the pitch-angle commands in the combined baseline and TFB control system.

Similar results (not shown) are obtained with the more modest $K_{P x}=0.007556 \mathrm{rad} /(\mathrm{m} / \mathrm{s}) \mathrm{TFB}$ gain. Here, the generator speed and power excursions are not as badly exacerbated, but there is also less improvement in the damping of the barge-pitch motion.

The simple model I describe in this section is routinely applied in the design of TFB damping control algorithms
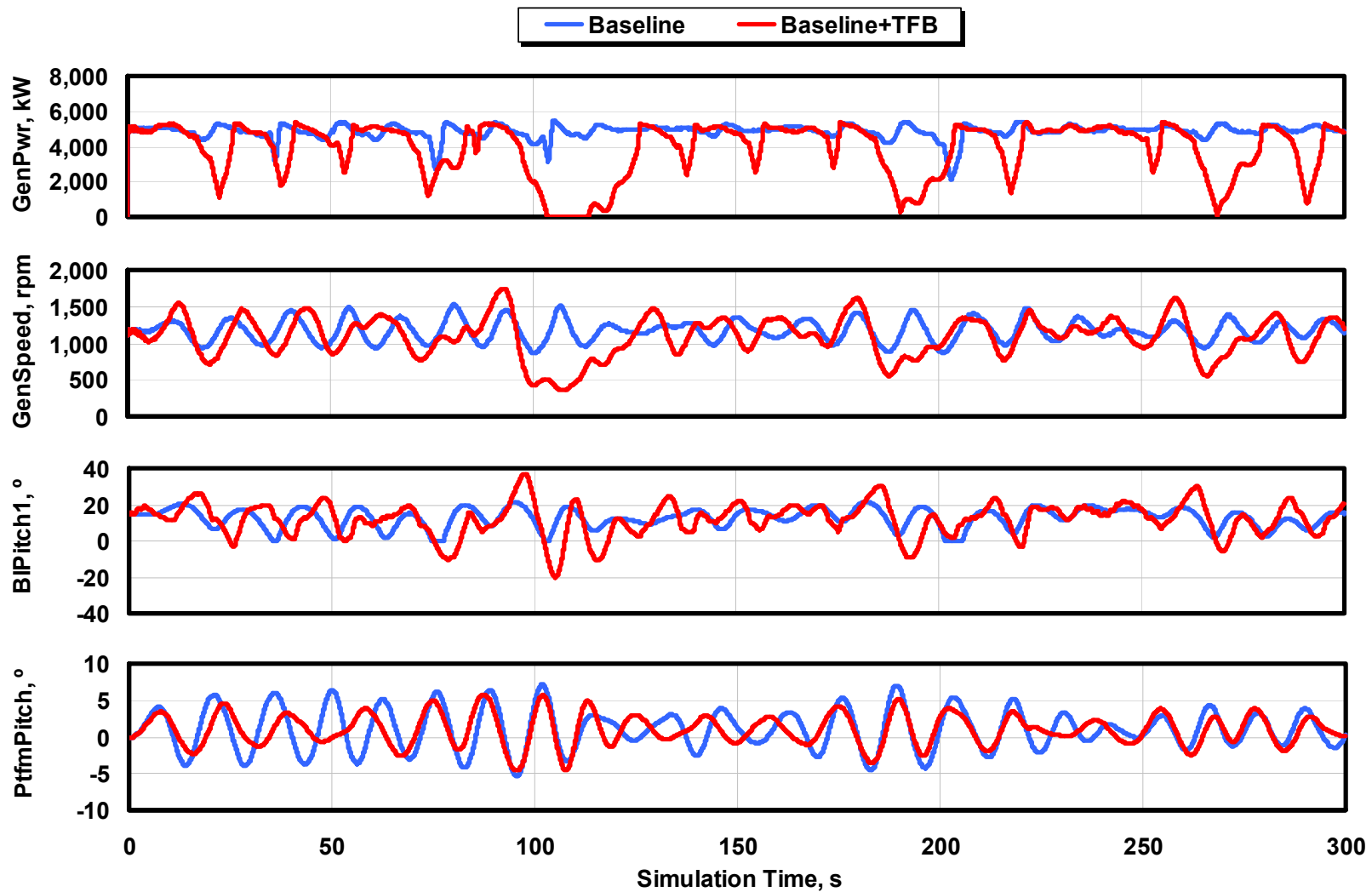

Figure 5. System response with and without a tower-feedback control loop. 
for land-based wind turbines. But, because the amplitude of the overall tower motion is less in land-based turbines, the problem with generator speed and power excursions is less of an issue. Instead, the control system designer for land-based wind turbines must make a basic trade-off between improved tower damping and increased generator speed and power excursions. For the floating system considered in this work, however, the severity of the tower-top motions induced by the barge's movement with surface waves renders the conventional TFB damping control system ineffective.

\section{B. Active Pitch-to-Stall Speed-Control Regulation}

As described in Section I, the problem to be addressed is that the reduction in steady-state rotor thrust with increasing wind speed in Region 3, which occurs as a result of variable blade-pitch-to-feather speed-control regulation, may introduce negative damping in the platform-pitch mode. This implies that variable blade-pitch-tostall speed-control regulation may damp the barge-pitch motions more effectively because drag (and hence thrust) increase as power is shed (to regulate speed) in increasing relative winds in wind turbines controlled by an active pitch-to-stall system. Although variable blade-pitch-to-stall speed-control regulation has been shown to work effectively in simulation, it has not been widely pursued in the wind industry because of the "uncertainty that remains in the theoretical understanding of stalled rotor aerodynamics" as pointed out by Bossanyi. ${ }^{12}$ In spite of this uncertainty, I tested the effects of active pitch-to-stall speed-control regulation for the floating wind barge concept.

Before pursuing the design of the pitch-to-stall controller, I decided to smooth the airfoil-data coefficients (as presented in Ref. 2) near stall to eliminate the existing fluctuations that could have led to numerical problems in the blade-element / momentum (BEM) aerodynamic-induction solution algorithm. I modified the airfoils by manually manipulating the lift coefficients.

Once the airfoil data were corrected, I redeveloped the full-span rotor-collective blade-pitch controller according to the same procedure I used to arrive at the blade-pitch-to-feather speed-control gains (see Ref. 2). The blade-pitch angles that produce the rated mechanical power are negative- and double-valued over the wind-speed range of Region 3, first decreasing, then increasing, with increasing wind speed. By being double-valued, it is impossible to use the same gain-scheduling law I implemented in the active pitch-to-feather controller. But because, the variation in blade-pitch sensitivity across Region 3 is less pronounced, gain scheduling is less of a requirement. Instead, I chose constant gains. These gains are smaller in magnitude than the pitch-to-feather gains at rated because the blade-pitch sensitivity — or control authority — is higher in pitch-to-stall operation. I incorporated the blade-pitch-tostall speed-regulation controller into my FAST with AeroDyn and HydroDyn simulations through a simple modification of the baseline control system.

As in Section III.A, I tested the system response of the NREL 5-MW wind turbine mounted atop the ITI Energy barge with this new control system at a variety of wind and wave conditions. Figure 6 compares the active pitch-tofeather and active pitch-to-stall system responses for the simulation with the same wind and wave conditions applied to the simulations presented in Figure 5 (i.e., an $18-\mathrm{m} / \mathrm{s}$ stochastic wind, a $3.673-\mathrm{m}$ significant wave height, and a 13.376-s peak spectral period). Again, I ran the simulations with all appropriate and available DOFs enabled, but without considering the rotor-mass imbalance or the increased blade structural-damping ratio.

As shown in Figure 6, active blade-pitch-to-stall control regulates generator speed-and hence electrical power-very well. It performs even better than the baseline active blade-pitch-to-feather controller. It does not, however, dampen the barge-pitch motions as intended. In fact, the barge-pitch motions are exaggerated in comparison to the response using the baseline active pitch-to-feather controller. This seemingly contradictory result can be understood by examining the barge-pitch damping ratios resulting from the active pitch-to-stall control. As for the pitch-to-feather system, the thrust sensitivity to wind speed ( $\partial T / \partial V)$ can be found by using the open-loop and ideal closed-loop methods, and both methods can be used to estimate the barge-pitch damping ratios. The results of these calculations are presented in Figure 7.

In Figure 7, the barge-pitch damping ratios associated with the pitch-to-stall system are plotted along with the original values presented in Figure 4 for the pitch-to-feather system. Because the two systems are identical below rated wind speed, so are the barge-pitch damping ratios. Above rated wind speed, however, the pitch-to-stall ratios diverge from the pitch-to-feather ratios. Unlike the pitch-to-feather values, the barge-pitch damping ratio remains positive-valued across control regions for the ideal closed-loop pitch-to-stall method because the thrust sensitivity to wind speed remains positive-valued. In the pitch-to-stall system slightly above rated, the open- and ideal closedloop bounds imposed by the barge-pitch damping ratios converge toward each other and remain at or near $2.5 \%$ across the remainder of Region 3.

As I mentioned at the end of Section II, with real blade-pitch-control speed regulation above rated wind speed, the actual damping ratio will lie somewhere between the bounds imposed by the open- and ideal closed-loop results. This implies that the real blade-pitch-to-stall controller, regardless of its gains, will give the system a slightly stable 

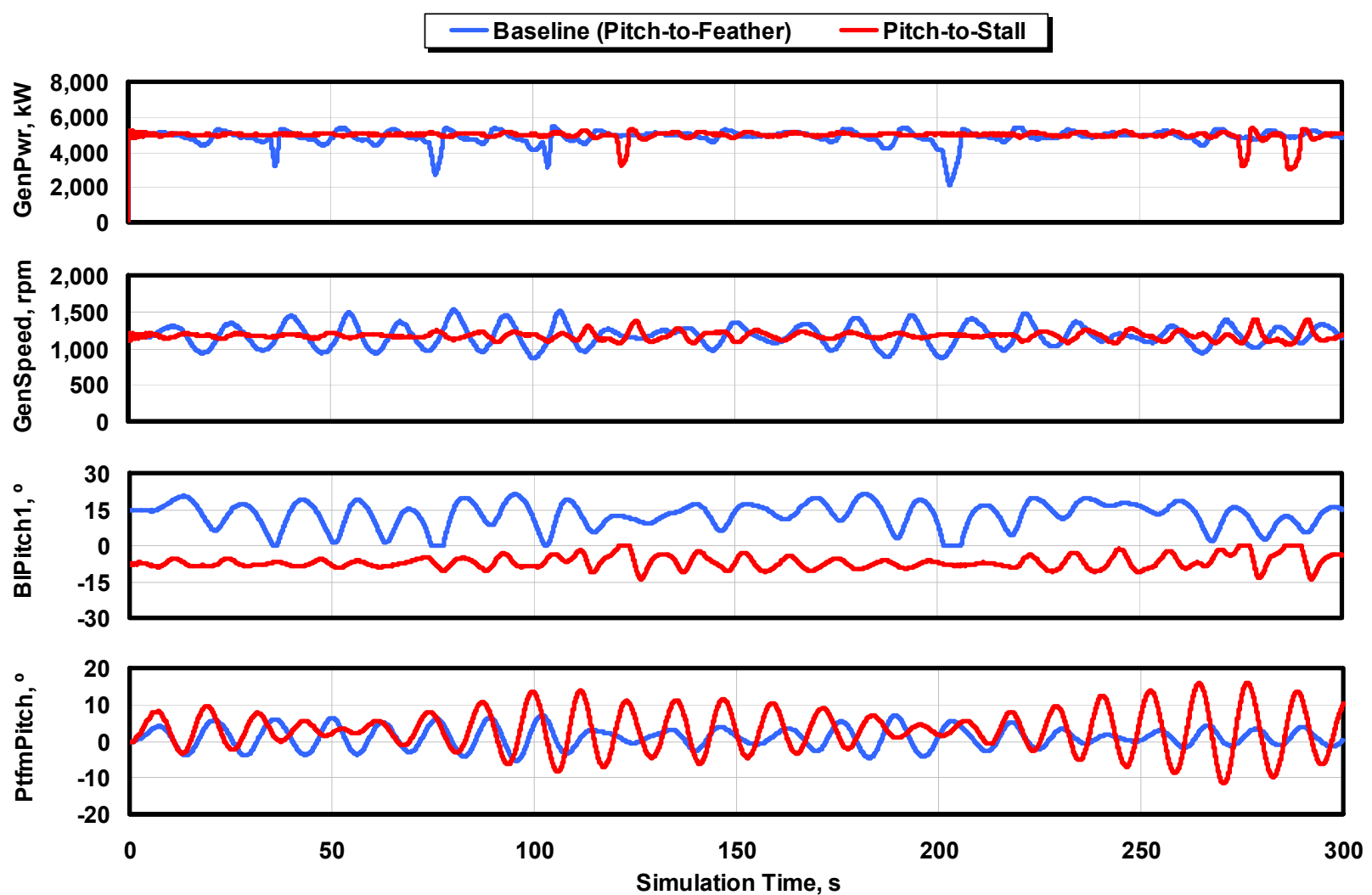

Figure 6. Comparison of pitch-to-feather and pitch-to-stall system responses.

barge-pitch damping ratio near 2.5\% across Region 3, starting just above rated. Moreover, because the barge-pitch motions for the pitch-to-stall system are larger than those for the pitch-to-feather system in the time histories presented in Figure 6, I can conclude that the real blade-pitch-to-feather speed controller actually has an effective damping ratio higher than $2.5 \%$ (at least for the conditions considered). In other words, the real pitch-to-feather barge-pitch damping ratio is actually much greater than that predicted by the ideal closed-loop results. It is still, however, beneficial to increase the damping as much as possible.

One possibility for increasing the barge-pitch damping through active pitch-to-stall control is to tailor the airfoildata coefficients so that rotor thrust increases more with wind speed in Region 3 than what resulted with the existing airfoils. Experimental data from NREL's Phase VI Unsteady Aerodynamics Experiment (UAE), ${ }^{13}$ which tested a passive stall-regulated wind turbine in the National Full-Scale Aerodynamics Complex at the National Aeronautics and Space Administration (NASA) Ames Research Center, showed a nearly steady increase in rotor thrust with wind speed from cut-in to cut-out. This would translate into a nearly constant steady-state thrust sensitivity to wind speed, $\partial T / \partial V$, across all wind speeds for the UAE wind turbine. If the NREL 5-MW wind turbine were modified to behave comparably (e.g., to make its thrust sensitivity to wind speed in Region 3 similar to that seen in Region 2), the ideal closed-loop barge-pitch damping ratio would increase to about $15 \%$ in Region 3 . This is slightly higher damping than the open-loop damping ratio achieved with active pitch-to-feather control. To achieve the necessary augmentation in rotor thrust, however, the existing airfoils will need to be modified and the rotor will need to be redesigned. Both tasks are beyond the scope of this work. I also suspect that it would be quite difficult to achieve damping ratios much above 15\% through rotor-thrust augmentation and active pitch-to-stall speed regulation, even though a higher amount of damping is desirable.

One might also think that combining the controller developed in this section with the TFB control loop developed in Section III.A would be another way to improve the barge-pitch damping through active pitch-to-stall speed-regulation control. But unfortunately, a pitch-to-stall control system cannot be combined with a classic TFB control loop for two reasons. First, the thrust sensitivity to rotor-collective blade pitch changes sign midway through Region 3, implying that the TFB control gain would also have to change sign midway through Region 3 . Otherwise, the TFB control loop would actually act to reduce the effective platform-pitch damping in certain operating regions. Second, the magnitude of the thrust sensitivity to blade pitch is much smaller with pitch-to-stall control than with 


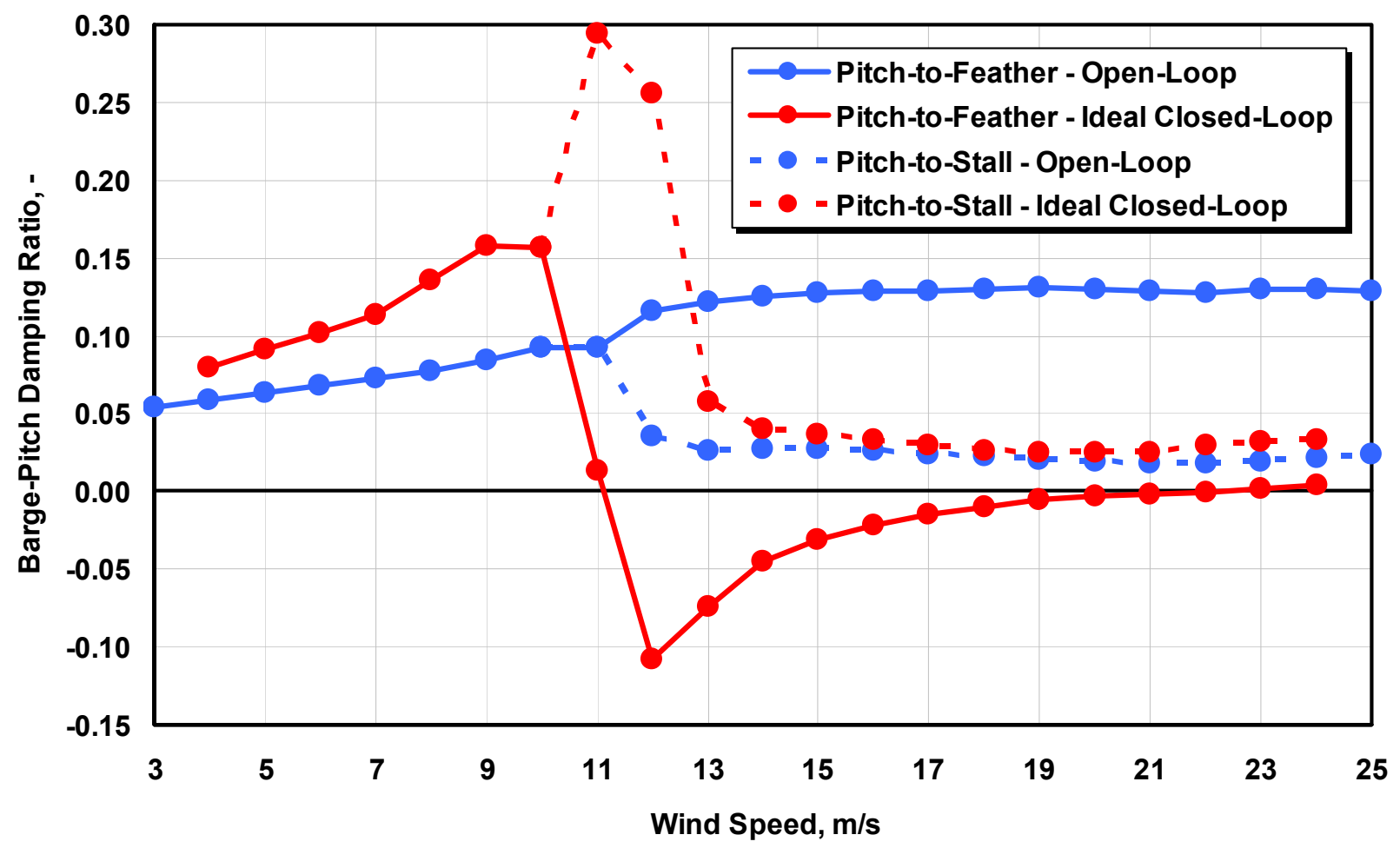

Figure 7. Pitch-to-feather and -stall barge-pitch damping ratios.

pitch-to-feather control. This implies that one could not achieve any significant increase in platform-pitch damping without very large control gains and resulting blade-pitch-rate requirements.

\section{Detuning the Gains in the Pitch-to-Feather Controller}

Neither the addition of the TFB control loop presented in Section III.A nor the modification to pitch-to-stall rotor-speed regulation presented in Section III.B gave satisfactorily improved the barge-pitch response. This section describes one more approach I took to improve the platform-pitch damping of the ITI Energy wind barge concept through conventional wind turbine control methods.

This control strategy was the simplest modification I made to the baseline control system developed in Ref. 2 , involving only a reduction of gains in the active blade-pitch-to-feather controller. The basic premise behind this control strategy is the understanding that reducing the gains in the rotor-speed controller will cause the floating wind turbine system to behave less like the results for the ideal closed-loop pitch-to-feather method, and more like the results for the open-loop control method. Because of knowledge about barge-pitch damping ratios acquired from Figure 4 or Figure 7, this end result is important.

As in the isolated rigid-body platform-pitch response, the idealized PI-based rotor-speed controller responds as a second-order system with a natural frequency, $\omega_{\varphi n}$, and damping ratio, $\zeta_{\varphi}{ }^{2}$. To maintain a reasonable relationship between the proportional and integral gains in the rotor-speed control system, I reduced the gains by choosing a smaller controller-response natural frequency $\left(\omega_{\varphi n}\right)$. I preserved the recommended controller damping ratio $\left(\zeta_{\varphi}=0.6\right.$ to 0.7$)$. The recommended value found in Ref. 14 , and the value selected for the baseline control system, ${ }^{2}$ of $\omega_{\varphi n}=$ $0.6 \mathrm{rad} / \mathrm{s}$ is slightly above the barge-pitch natural frequency of $\omega_{x n}=0.5420 \mathrm{rad} / \mathrm{s}$ (see Section II). This relationship between frequencies has the potential to introduce negative damping of the barge-pitch mode. Larsen and Hanson ${ }^{15}$ found that the smallest controller-response natural frequency must be lower than the smallest critical supportstructure natural frequency to ensure that the support structure motions of an offshore floating wind turbine with active pitch-to-feather control remain positively damped.

Reducing $\omega_{x n}$ by one-third will ensure that the controller-response natural frequency is lower than the bargepitch natural frequency and also lower than wave-excitation frequency of all but the most severe sea states. Using the properties for the NREL 5-MW wind turbine, I used $\omega_{\varphi n}=0.4 \mathrm{rad} / \mathrm{s}$ and $\zeta_{\varphi}=0.7$ to derive the reduced (detuned) gains. As in the baseline control system, ${ }^{2}$ I used the upper limit of the recommended damping ratio range $\left(\zeta_{\varphi}=0.7\right)$ 
to compensate for neglecting negative damping from the generator-torque controller in the determination of the proportional gain.

As in Sections III.A and III.B, I tested the system response of the NREL 5-MW wind turbine mounted atop the ITI Energy barge with this new control system. Figure 8 compares the system responses with the detuned and original (baseline) blade-pitch-to-feather gains for a simulation with the same wind and wave conditions used in the simulations presented in Figure 5 and Figure 6 (i.e., an 18-m/s stochastic wind, a 3.673-m significant wave height, and a 13.376-s peak spectral period). As before, I ran the simulations with all appropriate and available DOFs enabled, but without considering the rotor-mass imbalance or the increased blade structural-damping ratio.

As shown in Figure 8, the detuned blade-pitch control system is marginally effective at reducing the barge-pitch motions. Furthermore, it attains this positive performance without negatively affecting the generator speed and power excursions. As a matter of fact, the generator speed and power excursions have actually been diminished. And all of this has been accomplished with a reduction in blade-pitch duty cycle!

There is an upper bound, though, to the amount of improvement in the barge-pitch damping that is attainable with a basic detuning of the blade-pitch control system gains. That upper bound is simply the amount of damping shown in Figure 4 or Figure 7 for the open-loop pitch-to-feather control system, or roughly 13\% in Region 3.

In addition, one cannot expect that further and further reductions in the blade-pitch controller gains will continue to improve the damping of the barge-pitch motions without eventually exacerbating the excursions in the system response. This is because the rotor-speed error is unstable in the open-loop (uncontrolled) scenario in Region 3. (The rotor-speed error response is negatively damped if all blade-pitch control gains are zero.) To confirm this behavior, I reran simulations with detuned blade-pitch control gains derived from varying values of $\omega_{\varphi n}$, from 0.1 to $0.5 \mathrm{rad} / \mathrm{s}$ in steps of $0.1 \mathrm{rad} / \mathrm{s}$. As expected, with $\omega_{\varphi n}=0.1 \mathrm{or} 0.2 \mathrm{rad} / \mathrm{s}$ the system responses (not shown) exhibited much higher excursions in barge-pitch, generator speed, and electrical power output. With $\omega_{\varphi n}=0.5 \mathrm{rad} / \mathrm{s}$ and $\omega_{\varphi n}=$ $0.3 \mathrm{rad} / \mathrm{s}$, I obtained responses (not shown) very similar to the system responses obtained for gains derived with $\omega_{\varphi n}$ $=0.4 \mathrm{rad} / \mathrm{s}$. (The barge-pitch damping from the simulation with $\omega_{\varphi n}=0.4 \mathrm{rad} / \mathrm{s}$ was slightly better than the damping with $\omega_{\varphi n}=0.3$ or $0.5 \mathrm{rad} / \mathrm{s}$.)
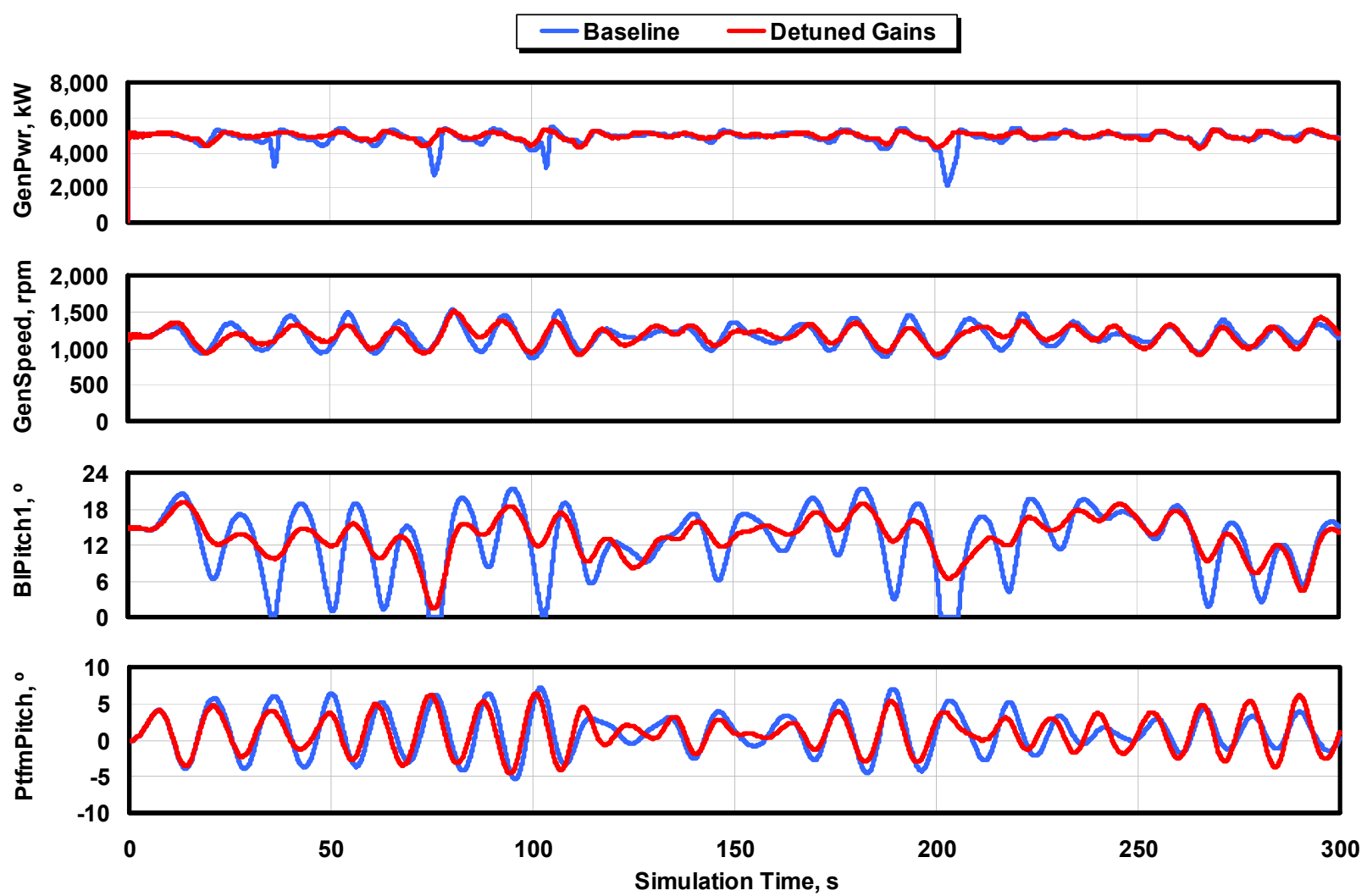

Figure 8. System responses with and without detuned blade-pitch control gains. 


\section{Other Ways to Improve the Pitch Damping with Turbine Control}

As demonstrated in Section III, conventional wind turbine control methodologies are limited in what they can do to improve the platform-pitch motions while limiting rotor-speed excursions of the ITI Energy wind barge concept. A number of other unconventional methods are also worth considering. Because a quantitative consideration of each method is beyond the scope of this work, I leave these considerations for future work. But this section highlights some of the possibilities.

I. Edwards of ITI Energy proposed one idea for an unconventional wind turbine control system. Edwards suggested that part of the problem with the barge-pitch damping in Region 3 might be that the generator is already operating at full (rated) power, so that there is no "head room" for absorbing more power as the barge pitches into the wind as a result of wave excitation. This implies that it might be better to regulate to some "below-rated" power level across all (even high) wind speeds to leave room for absorbing more power. This would, perhaps, permit the wind turbine rotor to capture not only wind power, but some wave power as well. Assessing this control strategy would require a study that examines the trade-off between improving the damping of the barge and reducing the capacity factor of the wind turbine.

Another unconventional wind turbine control strategy, proposed by Dr. R. Thresher of NREL, would be to use nacelle-yaw actuation, instead of blade-pitch actuation, to regulate the rotor speed of the turbine. This strategy could eliminate the problems from the drop in steady-state rotor thrust with increasing wind speed above rated resulting from blade-pitch-to-feather control. One would, however, have to determine whether the gyroscopic moments induced by the required yaw rates would have undesirable consequences.

A simple, but unconventional, modification to the control strategy would be to change Region 3 from a constant generator power to a constant generator-torque control region. With this change, the generator-torque controller would not introduce negative damping in the rotor-speed response (which must be compensated by the blade-pitch controller), and so, might reduce the rotor-speed excursions. Larson and Hanson ${ }^{15}$ demonstrated the effectiveness of this modification for one offshore floating wind turbine concept. This change, however, would not improve the barge-pitch damping.

Conventional wind turbine control methodologies rely on the independent development and concatenation of multiple single-input, single-output (SISO) proportional-integral-derivative-based (PID-based) control loops that use the conventional turbine actuators of blade pitch, generator torque, and nacelle yaw (and, as required, shaft brakes and other actuators). Naturally, modern control theories, such as disturbance-accommodating control (DAC), ${ }^{16}$ offer the potential to bring about improved performance. Previous controls studies by Stol, ${ }^{17}$ Hand, ${ }^{18}$ and Wright ${ }^{19}$ have demonstrated the applicability of combining a state estimator, a wind-disturbance estimator, and full-state feedback using DAC to develop multiple-input, multiple-output (MIMO) state-space-based control systems for mitigating dynamic loads and stabilizing flexible modes of land-based wind turbines without compromising energy capture. But these studies have not yet been extended to offshore floating wind turbines.

Through MIMO state-space-based control, it may be possible to enhance rotor-speed regulation and platformpitch damping through unified control of the generator torque and blade-pitch angles. For example, because rotorspeed regulation requires a blade-pitch command that is opposite of the one required to add damping to the bargepitch motion (see Section III.A), it might be possible to develop a combined generator-torque and blade-pitch controller to address both objectives simultaneously. The generator-torque commands may be able to mitigate the rotor-speed excursions while the blade-pitch commands attempt to augment aerodynamic rotor thrust to dampen the platform-pitch motion. When used in conjunction with off-axis flow through nacelle-yaw actuation, it may also be possible to introduce platform-roll damping through the blade-pitch commands (and thrust augmentation).

Rotor-collective blade-pitch control can be used to adapt rotor thrust, which induces a moment on the floating platform through the hub-height moment arm, but independent blade-pitch control may also be useful. For example, independent blade-pitch control can be used to introduce pitching moments within the rotor itself through asymmetric aerodynamic loading of the rotor. If developed properly, it may be possible to use such a moment to counteract the hydrodynamic pitching loads on the platform brought about by surface waves.

Reference 1 discusses other design alterations, beyond wind turbine control, that may be applied to improve the response of the floating wind barge system.

\section{Conclusion}

In this paper, I presented the influence of conventional wind turbine blade-pitch control actions on the pitch damping of the NREL 5-MW baseline wind turbine mounted atop the ITI Energy barge. I was concerned that the drop in steady-state wind turbine rotor thrust with wind speed above rated would lead to negative damping of the barge-pitch mode and contribute to the large system-pitch motions. 
I demonstrated that neither the addition of a control loop through feedback of tower-top acceleration nor the modification to pitch-to-stall rotor-speed regulation satisfactorily improved the barge-pitch response. The latter modification helped me conclude, however, that the actual barge-pitch damping was considerably greater than that implied by the steady-state rotor thrust response, but that it was still beneficial to increase the damping as much as possible. I also showed that detuning the gains in the baseline blade-pitch-to-feather controller helped, but still did not entirely resolve the barge-pitch-motion problem.

\section{Acknowledgments}

I would like to thank everyone who helped with this work, including Ian Edwards of ITI Energy for sponsoring the loads-analysis activities and Professor Nigel Barltrop and Willem Vijfhuizen of the Universities of Glasgow and Strathclyde for developing the ITI Energy barge and mooring system concept. Thank you also to Torben Larsen of Risø National Laboratory and the Technical University of Denmark for introducing me to the importance of the role that a variable blade-pitch-to-feather control system can play in offshore floating wind turbines and to Lee Jay Fingersh and Dr. Alan Wright for their guidance and advice in my controls-development activities. I also thank my $\mathrm{Ph}$.D. committee at the University of Colorado at Boulder for evaluating this project and Rene Howard, Stefanie Woodward, and Bonnie Jonkman of NREL for editing this paper to make it much more readable.

This work was performed at NREL in support of the U.S. Department of Energy under contract number DEAC36-99-GO10337 and in support of a Cooperative Research and Development Agreement (CRD-06-178) with ITI Energy.

\section{References}

${ }^{1}$ Jonkman, J. M. and Buhl, M. L., Jr., "Loads Analysis of a Floating Offshore Wind Turbine Using Fully Coupled Simulation," WINDPOWER 2007 Conference and Exhibition, Los Angeles, California, 3-6 June 2007 [CD-ROM], Washington, D.C.: American Wind Energy Association, June 2007, NREL/CP-500-41714, Golden, CO: National Renewable Energy Laboratory.

${ }^{2}$ Jonkman, J., Butterfield, S., Musial, W., and Scott, G., Definition of a 5-MW Reference Wind Turbine for Offshore System Development, NREL/TP-500-38060, Golden, CO: National Renewable Energy Laboratory, February 2007 (to be published).

${ }^{3}$ Vijfhuizen, W. J. M. J, Design of a Wind and Wave Power Barge, M.S. Dissertation, Department of Naval Architecture and Mechanical Engineering, Universities of Glasgow and Strathclyde, Glasgow, Scotland, September 2006.

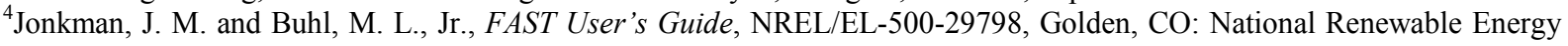
Laboratory, October 2004.

${ }^{5}$ Laino, D. J. and Hansen, A. C., User's Guide to the Wind Turbine Dynamics Aerodynamics Computer Software AeroDyn, Salt Lake City, UT: Windward Engineering LLC, Prepared for the National Renewable Energy Laboratory under Subcontract No. TCX-9-29209-01, December 2002.

${ }^{6}$ Moriarty, P. J. and Hansen, A. C., AeroDyn Theory Manual, NREL/EL-500-36881, Golden, CO: National Renewable Energy Laboratory, December 2005.

${ }^{7}$ Lee, C. H. and Newman, J. N., WAMIT ${ }^{\circledR}$ User Manual, Versions 6.3, 6.3PC, 6.3S, 6.3S-PC, WAMIT, Inc., Chestnut Hill, MA, USA, 2006.

${ }^{8}$ Jonkman, J. M. and Sclavounos, P. D., "Development of Fully Coupled Aeroelastic and Hydrodynamic Models for Offshore Wind Turbines," 44 ${ }^{\text {th }}$ AIAA Aerospace Sciences Meeting and Exhibit, 9-12 January 2006, Reno, NV, AIAA Meeting Papers on Disc [CD-ROM], Reston, VA: American Institute of Aeronautics and Astronautics, January 2006, AIAA-2006-995, NREL/CP500-39066, Golden, CO: National Renewable Energy Laboratory.

${ }^{9}$ Jonkman, J. M. and Buhl, M. L., Jr., "Development and Verification of a Fully Coupled Simulator for Offshore Wind Turbines," 45 ${ }^{\text {th }}$ AIAA Aerospace Sciences Meeting and Exhibit, 8-11 January 2007, Reno, NV, AIAA Meeting Papers on Disc [CD-ROM], Reston, VA: American Institute of Aeronautics and Astronautics, January 2007, AIAA-2007-212, NREL/CP-50040979, Golden, CO: National Renewable Energy Laboratory.

${ }^{10}$ Nielsen, F. G., Hanson, T. D., and Skaare, B., "Integrated Dynamic Analysis of Floating Offshore Wind Turbines," Proceedings of OMAE2006 $25^{\text {th }}$ International Conference on Offshore Mechanics and Arctic Engineering, 4-9 June 2006, Hamburg, Germany [CD-ROM], Houston, TX: The American Society of Mechanical Engineers (ASME International) Ocean, Offshore and Arctic Engineering (OOAE) Division, June 2006, OMAE2006-92291.

${ }^{11}$ Kristiansen, E., Hjulstad, Å., and Egeland, O., "State-Space Representation of Radiation Forces in Time-Domain Vessel Motions," Ocean Engineering, Vol. 32, 2005, pp. 2195-2216.

${ }^{12}$ Bossanyi, E. A., "Wind Turbine Control for Load Reduction,” Wind Energy, Vol. 6, No. 3, June 2003, pp. $229-244$.

${ }^{13}$ Hand, M. M., Simms, D. A., Fingersh, L. J., Jager, D. W., Cotrell, J. R., Schreck, S., and Larwood, S. M., Unsteady Aerodynamics Experiment Phase VI: Wind Tunnel Test Configurations and Available Data Campaigns, NREL/TP-500-29955, Golden, CO: National Renewable Energy Laboratory, December 2001.

${ }^{14}$ Hansen, M. H., Hansen, A., Larsen, T. J., Фye, S., Sørensen, and Fuglsang, P., Control Design for a Pitch-Regulated, Variable-Speed Wind Turbine, Risø-R-1500(EN), Roskilde, Denmark: Risø National Laboratory, January 2005. 
${ }^{15}$ Larsen, T. J. and Hanson, T. D., "A Method to Avoid Negative Damped Low Frequent Tower Vibrations for a Floating, Pitch Controlled Wind Turbine," Journal of Physics: Conference Series, The Second Conference on The Science of Making Torque From Wind, Copenhagen, Denmark, 28-31 August 2007, [online journal], Vol. 75, 2007, 012073, URL: http://www.iop.org/EJ/article/1742-6596/75/1/012073/jpconf7_75_012073.pdf?request-id=SpEuhRBu3BG0xV3r2wi7Kg, [cited 28 August 2007].

${ }^{16}$ Johnson, C. D., "Theory of Disturbance Accommodating Controllers," Advances in Control and Dynamic Systems, Vol. 12, 1976.

${ }^{17}$ Stol, K. A., Dynamics Modeling and Periodic Control of Horizontal-Axis Wind Turbines, Ph.D. Dissertation, Department of Aerospace Engineering Sciences, University of Colorado, Boulder, CO, USA, 2001.

${ }^{18}$ Hand, M. M., Mitigation of Wind Turbine/Vortex Interaction Using Disturbance Accommodating Control, Ph.D. Dissertation, Department of Mechanical Engineering, University of Colorado, Boulder, CO, USA, December 2003, NREL/TP500-35172, Golden, CO: National Renewable Energy Laboratory.

${ }^{19}$ Wright, A. D., Modern Control Design for Flexible Wind Turbines, Ph.D. Dissertation, Department of Aerospace Engineering Sciences, University of Colorado, Boulder, CO, USA, July 2004, NREL/TP-500-35816, Golden, CO: National Renewable Energy Laboratory. 


\section{REPORT DOCUMENTATION PAGE}

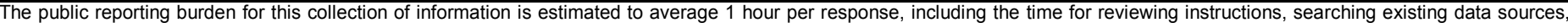

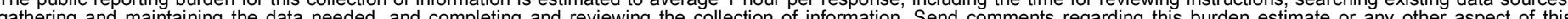

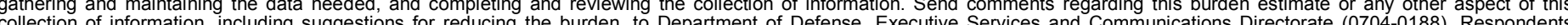

should be aware that notwithstanding any other provision of law, no $p$

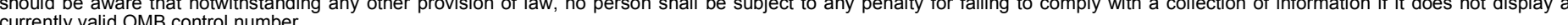

PLEASE DO NOT RETURN YOUR FORM TO THE ABOVE ORGANIZATION.

\begin{tabular}{l|l|l|l} 
1. REPORT DATE $(D D-M M-Y Y Y Y)$ & 2. & REPORT TYPE & 3. DATES COVERED (FrOm - TO)
\end{tabular}

March 2008

Conference paper

4. TITLE AND SUBTITLE

Influence of Control on the Pitch Damping of a Floating Wind

Turbine

6. AUTHOR(S)

J.M. Jonkman 5a. CONTRACT NUMBER

DE-AC36-99-G010337

5b. GRANT NUMBER

5c. PROGRAM ELEMENT NUMBER

5d. PROJECT NUMBER

NREL/CP-500-42589

5e. TASK NUMBER

WER82201

5f. WORK UNIT NUMBER

7. PERFORMING ORGANIZATION NAME(S) AND ADDRESS(ES)

National Renewable Energy Laboratory

1617 Cole Blvd.

8. PERFORMING ORGANIZATION REPORT NUMBER

NREL/CP-500-42589

Golden, CO 80401-3393

9. SPONSORING/MONITORING AGENCY NAME(S) AND ADDRESS(ES)

10. SPONSOR/MONITOR'S ACRONYM(S) NREL

11. SPONSORING/MONITORING AGENCY REPORT NUMBER

12. DISTRIBUTION AVAILABILITY STATEMENT

National Technical Information Service

U.S. Department of Commerce

5285 Port Royal Road

Springfield, VA 22161

13. SUPPLEMENTARY NOTES

14. ABSTRACT (Maximum 200 Words)

This paper presents the influence of conventional wind turbine blade-pitch control actions on the pitch damping of a wind turbine supported by an offshore floating barge with catenary moorings.

15. SUBJECT TERMS

wind energy; wind turbine; offshore wind energy; floating wind turbine platform; blade pitch control

\begin{tabular}{l}
\hline \multicolumn{3}{|l|}{ 16. SECURITY CLASSIFICATION OF: } \\
\hline \begin{tabular}{l|l|l|} 
a. REPORT & b. ABSTRACT & c. THIS PAGE \\
Unclassified & Unclassified & Unclassified \\
& & \\
\hline
\end{tabular}
\end{tabular}

\begin{tabular}{|c|c|}
\hline $\begin{array}{l}\text { 17. LIMITATION } \\
\text { OF ABSTRACT }\end{array}$ & $\begin{array}{l}\text { 18. NUMBER } \\
\text { OF PAGES }\end{array}$ \\
\hline UL & \\
\hline
\end{tabular}

19a. NAME OF RESPONSIBLE PERSON

19b. TELEPHONE NUMBER (Include area code) 